\title{
Laryngotracheoesophageal cleft type 1
}

INSERM

\section{Source}

INSERM. (1999). Orphanet: an online rare disease and orphan drug data base.

Laryngotracheoesophageal cleft type 1. ORPHA:93938

Laryngo-tracheo-esophageal cleft (LC) type 1 is a congenital respiratory tract anomaly characterized by a suprag lottic, interarytenoid cleft above the vocal folds with moderate respiratory symptoms. 